DOI: https://doi.org/10.24867/01GI01Milosavljevic

\title{
ULOGA I ZNAČAJ KROS FUNKCIONALNIH TIMOVA NA PRIMERU E - COMMERCE KOMPANIJE
}

\section{THE ROLE AND IMPORTANCE OF CROSS - FUNCTIONAL TEAMS ON THE EXAMPLE OF E - COMMERCE COMPANY}

\author{
Marko Milosavljević, Slobodan Morača, Fakultet tehničkih nauka, Novi Sad
}

\section{Oblast - INŽENJERSKI MENADŽMENT}

Kratak sadržaj- U poslovnom okruženju današnjice, najveći broj kompanija koristi timove kao sastvani deo sopstvene organizacione forme. Ovakav vid organizovanja im omogućava da na najbolji način iskoriste potencijale zaposlenih $i$ istovremeno realizuju prethodno propisane ciljeve. Rad će prikazati osnovne faktore koji utiču na uspešnost funkcionisanja tima u E-Commerce organizacijama.

Ključne reči : Timovi, Kros funkcionalni timovi, timski rad, E-Commerce, projektni menadžment

Abstract - In today's business environment, most of the companies are using teams as the basic organizational structure. This sort of organization allows them to deploy its employees' capabilities in the best possible way, while simultaneously working on realization of organizational goals. This paper will show key elements which can influence team's well functioning in an E-Commerce organization.

Keywords: Teams, Cross functional teams, Team work, E - Commerce, Project management

\section{UVOD}

Uslovi privređivanja današnjice odlikuju se visokim nivoom konkurentonsti. S obzirom na brzu prirodu promena, kompanije su prinuđene da im se u što kraćem vremenskom intervalu prilagode i prihvate ih kao mogućnost za ekspolataciju novih tržišnih okolnosti.

Kompanije koje blagovremeno ne identifikuju, a potom i ne iskoriste novonastale šanse, rizikuju svoj dalji tržišni opstanak.

Sve intenzivnija globalna konkurencija i konstantna potreba za inovacijama stvaraju pritiske koji utiču na formulaciju timova kao osnovnih elemenata organizacija. Upotreba timova, kao jednog od glavnih organizacionih jedinjenja, je postala svakodnevna pojava u mnogim kompanijama, nezavisno od privredne grane $\mathrm{u}$ kojoj određena kompanija obavlja svoju delatnost.

Timovi su naročito karakteristični u modernim organizacijama u okviru kojih je neophodno angažovati više pojedinaca sa različitim setom veština, kako bi se osiguralo sticanje i naposletku održavanje konkurentske prednosti.

\footnotetext{
NAPOMENA:

Ovaj rad proistekao je iz master rada čiji mentor je bio prof. dr Slobodan Morača.
}

Kombinovanjem više različitih veština u okviru timova, ostvaruje se efekat diverzifikacije, kako mišljenja, tako i potencijalnih rešenja novonastalih problema.

U tom smislu, polimerizacijom komplementarnih veština, tržišno orijentisane organizacije će potencijalno biti u mogućnosti da obogate svoj portfolio proizvoda i usluga $i$ tako obogate portfolio proizvoda i usluga i tako targetiraju nova do tada za njih nepostojeća tržita. Globalizacija svetske privrede i njenih tokova, kao i ubrzan razvoj savremenih tehnologija i interneta, su iznedrili potrebu za brze reakcije $\mathrm{i}$ odgovore kompanija na promenljive zahteve potrošača.

Trgovina upotrebom interneta kao glavnog medijuma, je postala uobičajena pojava i svakodnevno beleži rast. Kompanije koje plasiraju svoje proizvode i usluge na međunarodnom nivou, ukoliko pravovremeno identifikuju novonastale tržišne trendove, biće u mogućnosti da zabeleže dobre poslovne rezultate i na taj način ostvare željeni tržišni udeo. Razvoj mnogobrojnih internet portala za trgovinu je omogućio ponuđačima proizvoda različite vrste i namene, da ih lakše plasiraju. Postojanje velikog broja konkurenata sa istim ili sličnim proizvodnim portfoliom, zahteva od organizacija koje posluju u ovakvom okruženju kvalitetno postavljene i organizovane kros funkcionalne timove, koji predstavljaju preduslov opstanka ove vrste kompanija na tržištu.

Udruživanjem pojedinaca različitih, ali komplementarnih veština u ovako postavljene organizacione celine, koji će svakodnevnim aktivnostima obavljati različite kako tekuće, tako i projektne zadatke, moguće je kontrolisati određene poslovne parametre, ali i kontrolisanje kako postojećih, tako i potencijalnih konkurenata.

Ovakav pristup organizovanja, omogućava permanentan monitoring potencijalnih šansi, ali i eventualnih opasnosti. Istraživanje je sprovedeno u kompaniji New Plant d.o.o koja posluje u oblasti E - commerca. Kompanija raspolaže širokim proizvodnim asortimanom, koji sačinjava roba široke potrošnje. Svoje proizvode plasira na tržištu Evropske Unije, gde raspolaže sa 741,4 miliona potencijalnih potrošača.

Proizvodi se prodaju putem internet portala za trgovinu poput: Amazona (Nemačka, Ujedinjeno Kraljevstvo, Italija, Francuska i Španija), Real, Hood, E - Bay (Nemačka i Italija) i C Disount. Kompanija upošljava više od 80 ljudi koji su zaduženi da obavljaju različite funkcije i zadatke koji se odnose na prodaju, nabavku, podršku kupcima i dr. 


\section{UOPŠTENE NAPOMENE O TIMOVIMA}

Literatura je identifikovala pregršt različitih definicija timova, kao i elemenata koji imaju direktnog ili indirektnog uticaja na uspešnost rada tima. Protekla decenija se odlikuje drastičnom transformacijom organizacionih struktura širom sveta. Pored ekonomskih, strateških i tehnoloških faktora koji utiču na transformacioni proces, jedan od najuočljivijih aspekata je tekući pomak od rada usmerenog na pojedinačne potrebe zaposlenih na timsko usmereni rad [1]. Mnogobrojne organizacije nastoje da poboljšaju sopstvenu efikasnost uvođenjem timova. Stoga ih mnoge kompanije koriste zato što se pokazalo da udruživanje zaposlenih u timove utiče na povećanje satisfakcije kupaca, kvalitet proizvoda i usluga, sveopšte zadovoljstvo zaposlenih na radnom mestu, kao i da pospešuje kvalitet donošenih odluka [2].

Pojedina istraživanja [3] ukazuju da je efikasnost timskog rada rezultat dobro raspodeljenih zadataka u okviru tima, odgovarajućeg sastava tima i dostupnosti resursa, informacija i nagrada. Udruživanje zaposenih u timove, predstavlja vrlo popularan vid organizovanja, koji organizacije pre nego što implementiraju u sopstveni sistem rada treba pažljivo da promisle i formulišu, kako ne bi ostvarile kontra efekte. Uprkos doprinosu koji timovi mogu dati organizaciji, a koji se odnose na učenje i inovacije, samo uvođenje timova je vrlo kompleksno.

Pojedini timovi opravdavaju ili čak prevazilaze organizaciona očekivanja i ostvaruju daleko bolje rezultate od očekivanih [4] [5], dok drugi ne opravdavaju očekivanja i utiču na povećanje troškova i ostvarivanje negativnih rezultata na nivou organizacije [6]. Varijacije u značaju i učinku timova su prisutne i uočljive, ne samo među timovima u okviru organizacije, već i između samih organizacija, čija je organizaciona struktura postavljena na dati način. Tako na primer, organizacije čije se poslovanje odvija u visokodinamičnoj oblasti poput ECommerca, gotovo je ne moguće pokriti sve aktivnosti, bez udruživanja zaposlenih $\mathrm{u}$ timove, obzirom na turbulentnu prirodu ovog vida poslovanja i skupa poslova koji moraju biti pokriveni kako bi jedna ovakva organizacija mogla nesmetano da obavlja svoje aktivnosti. U današnje vreme, kompanije koje posluju na globalnom nivou su izložene mnogobrojnim pretnjama kao i visokom nivou nestabilnosti i konkurentnosti.

$\mathrm{U}$ tom smislu, veoma je važno da iznađu najbolja rešenja koja će implementirati kao akcione planove uz pomoć kojih će osigurati svoj dalji tržišni razvoj i opstanak. Efikasno suočavanje sa pretnjama i eksploatacija novonastalih tržišnih šansi, se u velikoj meri oslanja na agilnost timova i njen uticaj na njihove performanse. Agilnost tima se može definisati kao sposobnost timova da u kratkom roku odgovore na novonastale tržišne okolnosti [7], što rezultuje brzim reakcijama na tržištu na promenljive zahteve potrošača.

Ubrzan razvoj informacionih i telekomunikacionih tehnologija je olakšao saradnju timova, kako na internom tako i na eksternom nivou. Konvergencija ove vrste tehnologija je revolucionarizovala tradicionalne načine međusobne saradnje i rada i stvorila prostor za kreiranje novih oblika saradnje i komunikacije (npr. virtuelni timovi i organizacije), ali i kreiranje organizacija čiji se rad zasniva na elektronskom poslovanju (npr. elektronska trgovina $-e$-commerce)

\section{VRSTE TIMOVA}

S obzirom da se u okviru organizacijskog koncepta obavljaju različite aktivnosti, timovi se kreiraju spram trenutnih potreba organizacije, kako bi obavljali različita zaduženja i zadatke. Za koju vrstu timova će se određena organizacija opredeliti će prvenstveno zavisiti od vrste poslovanja koju obavlja, a pri tome i od obima zadataka koji mora da izvrši. Timove je moguće klasifikovati na više načina. Postoje stalni, privremeni, funkcionalni i interfunkcionalni timovi. Pojedina istraživanja aludiraju na činjenicu da autonomija predstavlja ključni element koji pravi razliku među timovima [8]. Autonomija podrazumeva do koje mere su radnici u mogućnosti da samostalno donesu odluke o tome kako i kada će obavljati delegirane zadatke.

U tom kontekstu moguće je napraviti distinkciju između sledećih vrsta timova:

- Tradicionalne radne grupe;

- Timovi za podsticanje učešća;

- Poluautonomne radne grupe;

- Samoupravni timovi;

- Samodefinisani timovi.

Pored ovih timova, postoje još mnoge vrste timova, od kojih će sledeće biti razmatrane:

- Interfunkcionalni timovi;

- Kros - funkcionalni timovi;

- Virtuelni timovi;

- Projektni tiomovi.

\section{E - COMMERCE}

Elektronska trgovina je revolucija koju mnogi industrijski i akademski stručnjaci veruju da će transformisati ponašanje i strukturu poslovanja kakvim ga mi danas znamo. Poslovne procese E- Commerca proizvode brojni podaci i kompjuterska tehnologija, koja omogućava njihovo prikupljanje i analizu. Kako bismo razumeli ove podatke i informacije prikupljene na ovaj način, neophodno je posedovanje vrhunskih analitičkih alata koji su u sposobnosti da obrade veliku količinu podataka (npr. program SAP). Najveća količina podataka u vezi sa $\mathrm{E}$ - Commercom se odnosi na ekonomske podatke.

Elektronska trgovina i poslovni procesi generišu podatke o cenama, ukupnim količinama, spremnosti potrošača na kupovinu kao i performanse tržišta. Analiza ovih faktora nudi istraživačima mogućnost da razrade modele za promenu strukture tržišta, identifikaciju kritičnih faktora koji rezultuju uspehom ili neuspehom organizacije, kao i sposobnost tumačenja brzine promena i usvajanja novih tehnologija podržanih od strane interneta itd.

Nije nikakva tajna da je E - Commerce bio glavni pokretač proizvodnje robe široke potrošnje u poslednjih nekoliko godina, ali ono što je manje jasno, je kako najbolje postaviti organizaciju da na adekvatan način odgovori na novonastale situacije i izazove. 
Ono što je najvažnije jeste kreiranje šansi za organizacije da lakše targetiraju svoje kupce na vrlo direktan način putem kreiranja elektronskih tržišta. Upotrebom sistema elektronske trgovine, prodavac može da održava inventar i da ga ažurira po pirjemu robe od dobavljača. Već više od dve decenije, organizacije su obavljale poslove elektronskim putem koristeći različita rešenja elektronske trgovine. E - Commerce je novonastali koncept, koji opisuje proces kupovine i prodaje ili razmene proizvoda, usluga i informacija putem računarskih mreža uključujući internet. Primarne pogodnosti koje nude online transakcije uključuju pogodnost, niže cene i manje vreme potrage za određenim proizvodima ili uslugama.Prema nekim projekcijama do 2020. godine E - Commerce će preći cifru od \$4 triliona [9]. Ovako brz razvoj i rast zahteva od organizacija koje posluju u ovom segmentu brze odgovore i reakcije kako bi opstale u ovom dinamičnom okruženju. E Commerce će i dalje biti glavni faktor promena u gotovo svim industrijskim oblastima, donoseći sa sobom sopstvene izazove. Ovo će zahtevati od organizacija koje se bave proizvodnjom robe široke potrošnje još brže tržišne reakcije.

\subsection{New Plant}

Kompanija New Plant d.o.o je osnovana 25.07.2017. godine u Novom Sadu. Glavna delatnost kompanije je prodaja proizvoda široke potrošnje posredstvom interneta. Prodaja se odvija posredstvom najvećih svetskih portala:

- Amazon (Nemačka, Francuska, Ujedinjeno Kraljevstvo, Italija i Španija);

- Ebay (Nemačka i Italija);

- Real.de;

- Cdiscount.fr;

- Hood.de.

Kompanija poseduje veliki asortima proizvoda široke potrošnje. Najveći fokus kompanije je stavljen na Nemačko tržište, obzirom da se u Nemačkoj nalazi skladište, odakle se porizvodi šalju kupcima. Kompanija konstantno teži da inovira svoj proizvodni porfolio, kako bi se probila na nova tržišta i na taj način doprla do novih kupaca.

\section{HIPOTEZE, METODOLOGIJA i REZULTATI}

Autori koji su se bavili problematikom efikasnosti rada timova su prepoznali mnoštvo elemenata koji se mogu smatrati ključnima kada je u pitanju više ili manje efikasna timska saradnja. Karakteristike, vrsta i svrha postojanja tima će mahom uslovljavati parametre koji će diktirati elemente uspešnosti njegovog rada i funkcionisanja.

Pregledom literature, identifikovani su neki od ključnih parametara koji se mogu posmatrati kao presudni kada je u pitanju efikasnost rada timova koji posluju u sektoru E - Commerca.

$\mathrm{Na}$ osnovu toga je razrađen istraživački model (Slika 2). Ukrštanjem ovih elemenata, uspostavljene su hipoteze u radu, sa efikasnošću rada tima kao centralnim konceptom. Ovakva postavka istraživanja je omogućila uvid, da li posmatrani faktori imaju uticaja na efikasnost rada ovako rada ovako organizovanih timova.

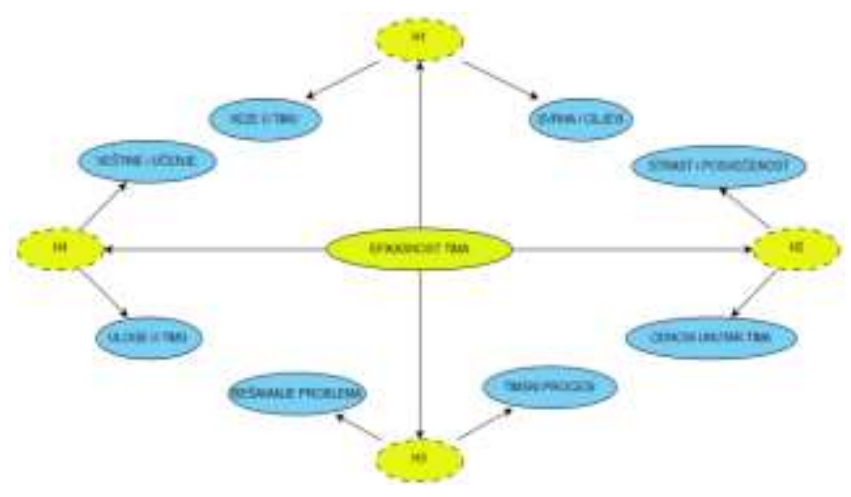

Slika 2. Istraživački model

H1: Jasno definisani svrha i ciljevi u okviru tima $u$ kombinaciji sa kvalitetno uspostavljenim vezama u timu imaju direktan uticaj na efikasnost rada tima.

H2: Strast i posvećenost radu zajedno sa dobrim odnosima unutar tima, imaju direktan uticaj na efikasnost rada tima.

H3: Sposobnost efektivnog rešavanja problema zajedno sa jasno definisanim timskim procesima, imaju direktan uticaj na efikasnost rada tima.

H4: Jasno definisane uloge u okviru tima u kombinaciji sa odgovarajućim veštinama i znanjima članova tima, imaju direktan uticaj na efikasnost rada tima.

\subsection{Metodologija}

Prethodnim pregledom literature koja se tiče funkcionisanja i načina rada timova, formiran je istraživački model. Na osnovu njega je došlo do dalje razrade elemenata $i$ faktora koji se mogu smatrati ključnim kada je u pitanju efikasno funkcionisanje timova. Istraživanje je sprovedeno u kompanij koja posluje u oblasti E - Commerca. Grupa zaposlenih organizovanih u kros funkcionalne timove (eng. CFT Cross Functional Teams) u Republici Srbiji u Novom Sadu je učestvovala u istraživanju.

Nivo responzivnosti je iznosio $84.37 \%$ od strane 8 timova, gde je svaki od timova sačinjen od 4 člana, ( $n=$ 27) od ukupno 32 radnika koji rade u analiziranom sektoru kompanije, od kojih su 40,7\% ispitanici muškog pola, a 59,3\% ispitanici ženskog pola.

Anketirani zaposleni obavljaju različite poslovne aktivnosti. Učesnici u studiji blisko sarađuju na različitim zadacima koji se odnose na marketing, istraživanje tržišta, poslovi nabavke, implementacija strateških planova od strane menadžmenta. Svakodnevno, klasterima se dodeljuju različiti projekti i zadaci koji se odnose na prethodno pomenute aktivnosti. Ovi zadaci zahtevaju ekspertizu iz različitih oblasti, kako bi se mogli uspešno izvršiti.

Svaki tim se sastoji od tri različite funkcionalne oblasti, $\mathrm{u}$ okviru koga su članovi oba pola i različitih nivoa obrazovanja kako bi se osigurala funkcionalna raznolikost. Istraživanje je sprovedeno upotrebom anketnog upitnika. Upitnici su u obliku čvrste kopije podeljeni zaposlenima u toku radnog vremena. 
Sadržali su jasna uputstva koja se odnose na način popunjavanja i predaje upitnika istraživaču. Učešće zaposlenih u istraživanju je bilo na dobrovoljnoj bazi.

\subsection{Rezultati}

$\mathrm{Na}$ osnovu posmatranih parametara, dobijeni su rezultati koji ukazuju na uticaj analiziranih elemenata na efikasnost rada tima. U nastavku rada biće prikazani rezultati postavljenih hipoteza.

H1: Na osnovu stepena korelacije $\mathrm{r}=0,939(\mathrm{p}=0,000)$ može se zaključiti da postoji značajna pozitivna korelacija između efikanosti rada tima i uspostavljanja jakih veza unutar tima u kombinaciji sa jasnom svrhom postojanja i ciljeva tima.

H2: Na osnovu stepena korelacije $\mathrm{r}=0,963(\mathrm{p}=0,000)$ može se zaključiti da postoji značajna pozitivna korelacija između efikanosti rada tima i strasti i posvećenosti prema radu u kombinaciji sa kvalitetno uspostavljenim odnosima unutar tima.

H3: Na osnovu stepena korelacije $\mathrm{r}=0,939(\mathrm{p}=0,000)$ može se zaključiti da postoji značajna pozitivna korelacija između efikasnosti rada tima i sposobnosti rešavanja problema u kombinaciji sa kvalitetno uspostavljenim timskim procesima.

H4: Na osnovu stepena korelacije $\mathrm{r}=0,948(\mathrm{p}=0,000)$ može se zaključiti da je četvrta hipoteza potvrđena jer postoji značajna korelacija između efikasnosti rada tima $i$ jasno definisanih uloga članova tima koji poseduju odgovarajuće veštine i sposobnost usvajanja novih znanja.

\section{ZAKLJUČNA RAZMATRANJA}

Analizom razmatrane tematike može se zaključiti da timovi i timski rad igraju ključnu ulogu u poslovanju organizacija čije se poslovanje odvija u intenzivno promenljivom okruženju kao što je poslovanje u oblasti E - Commerca. Timovi koji rade u ovoj vrsti organizacija su izloženi mnogobrojnim zadacima, koji ukoliko se ne tempiraju blagovremeno, ili se na pravi način ne iznađe odgovor za promenljive potrebe potrošača, može imati negativne efekte na poslovanje celokupne organizacije. Ono što se u današnje vreme nameće kao neminovnost je transformacija načina i vrste trgovine i njeno intenziviranje putem upotrebe elektronskih kanala. Na ovaj način organizacije su u mogućnosti da bez većih napora targetiraju veći broj potencijalnih kupaca i tako ostvare dobre poslovne rezultate.

Analiza dobijenih rezultata pokazuje da postoje elementi koji se mogu okarakterisati kao visoko kvalitetni kada je upitanju način rada $\mathrm{i}$ funkcionisanja timova $\mathrm{u}$ okviru kompanije New Plant d.o.o. Takođe je evidentno da kompanija mora da uloži odgovarajuće napore kako bi u budućnosti zadržala najbolje radnike $i$ na taj način smanjila fluktuaciju zaposlenih, ali i da bi privukla nove talente. Kompanije New Plant d.o.o ukoliko nastavi da raspolaže sa kvalitetnim kadrom, koji će permanentno nadgledati i kontrolisati rad konkurentskih ponuđača i pronalaziti nove proizvode kako bi obagatila svoj proizvodni portfolio biće u mogućnosti da osigura dugoročni rast i razvoj. Vođenjem politike konstantnog unapređenja procesa rada i izlaganja zaposlenih inovativnim tehnološkim dostignućima kreira se atmosfera koja podržava učenje i inovacije što može delovati kao motivišući faktor zaposlenima da $\mathrm{u}$ perspektivi ulože veće napore kako bi se poslovanje celokupne organizacije još više unapredilo.

\section{LITERATURA}

[1] Lawler, E. E., Mohrman, S. A., \& Ledford, G. E. (1992). Employee involvement and total quality management: Practices and results in Fortune 1000 companies. Jossey-Bass Inc Pub.

[2] Kirkman, B. L., \& Rosen, B. (1999). Beyond selfmanagement: Antecedents and consequences of team empowerment. Academy of Management journal, 42(1), 58-74.

[3] Hackman, J. R., \& Hackman, R. J. (2002). Leading teams: Setting the stage for great performances. Harvard Business Press.

[4] Brown, S. L., \& Eisenhardt, K. M. (1995). Product development: Past research, present findings, and future directions. Academy of management review, 20(2), 343-378.

[5] Kessler, E. H., \& Chakrabarti, A. K. (1996). Innovation speed: A conceptual model of context, antecedents, and outcomes. Academy of Management Review, 21(4), 1143-1191.

[6] AitSahlia, F., Johnson, E., \& Will, P. (1995). Is concurrent engineering always a sensible proposition?. IEEE Transactions on Engineering Management, 42(2), 166-170.

[7] Breu, K., Hemingway, C. J., Strathern, M., \& Bridger, D. (2002). Workforce agility: the new employee strategy for the knowledge economy. Journal of Information Technology, 17(1), 21-31.

[8] Simons, T., Pelled, L. H., \& Smith, K. A. (1999). Making use of difference: Diversity, debate, and decision comprehensiveness in top management teams. Academy of management journal, 42(6), 662673.

[9] https://www.oliverwyman.com/content/dam/oliverwyman/v2/events/2018/March/FROM THE_SPEED OF SOUND TO THE_SPEED OF_LIGHT.pdf (Pristupljeno u avgustu, 2018)

\section{Kratka biografija}

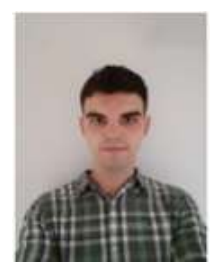

Marko Milosavljević je diplomirao na Fakultetu za ekonomiju i inženjerski menadžment u Novom Sadu 2017. godine. Autor je nekoliko radova iz oblasti marketinga, poslovnih komunikacija, projektnog menadžmenta i fenomena odliva mozgova. Njegovi istraživački radovi objavljeni su u lokalnim i međunarodnim časopisima i konferencijama. Master rad je odbranio 2018. godine na Fakultetu tehničkih nauka u Novom Sadu.

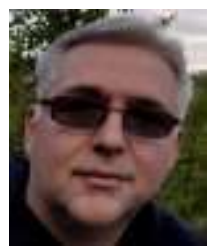

\section{Prof. dr Slobodan Morača}

Radi na Fakultetu tehničkih nauka. Autor je preko 80 naučno-stručnih radova. 